\title{
Evaluation of seismic effects on the landslide deposits of Monte Salta (Eastern Italian Alps) using distinct element method
}

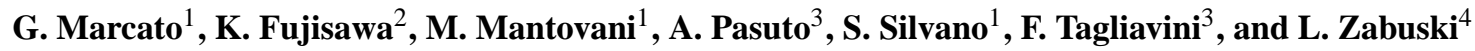 \\ ${ }^{1}$ National Research Council of Italy, Research Institute for Hydrological and Geological Hazard Prevention, Padova, Italy \\ ${ }^{2}$ Public Works Research Institute, Erosion and Sediment Control, Tsukuba, Japan \\ ${ }^{3}$ Geo Risk Joint Lab, Padova, Italy \\ ${ }^{4}$ Institute of Hydro-Engineering of the Polish Academy of Sciences, Gdansk, Poland
}

Received: 14 February 2007 - Revised: 28 September 2007 - Accepted: 28 September 2007 - Published: 22 November 2007

Abstract. The aim of the paper is to present the modelling of the ground effects of seismic waves on a large debris deposit lying on a steep mountain slope, with particular attention paid to the potential triggering of slope movements.

The study site is a mass of 2.5 million $\mathrm{m}^{3}$ rock fall deposit, named "Monte Salta Landslide", located on the northern slope of the Vajont valley, at the border between Veneto and Friuli Venezia Giulia regions in north-eastern Italy.

Several historical landslide events were reported in the area in the past, first one dating back to the 17 th century. The landslide deposit completely mantles the slope with a thick cover of rock blocks.

The Mt. Salta landslide is conditioned by the presence of Mt. Borgà regional thrust, which uplifts Jurassic limestone on the top of Cretaceous rock units. Above the thrust zone, folded and highly fractured rock mass dips steeply towards the slope free face, producing highly unstable setting.

The study area has been classified as high seismic hazard and different vulnerable elements can be affected by the remobilisation of debris, among which a village, a national road and a big quarry that was opened, with the intent to exploit the part of the landslide deposit for construction purposes.

In this study, numerical analysis was performed, to simulate the slope behaviour using distinct element method and applying UDEC code. The 2-D models were built on three cross-sections and elasto-plastic behaviour was assumed, both for rock matrix and discontinuities. The earthquake effect was modelled in pseudo-dynamic way, i.e. by magnifying the acceleration and applying also its horizontal component. The expected seismic acceleration in the study area was calculated on the basis of previous studies as equal to $0.28 \mathrm{~g}$.

Correspondence to: G. Marcato

(marcato@irpi.cnr.it)
The results proved that the increase of the vertical component alone has a small influence on the deformational behaviour of the system. Hence, the acceleration vector was deviated at $5^{\circ}$ and then at $10^{\circ}$ from the vertical. A small increment of the displacement was observed in the first case, whereas very large movements occurred in the second. Therefore, it can be concluded that, besides the magnitude of the earthquake, even small seismic waves in horizontal direction could trigger significant movements and therefore hazardous conditions. The modelled scenario should be helpful for planning of the functional countermeasure works and civil defence evacuation plan.

\section{Introduction}

Landslides triggered by earthquakes such as rock falls are the most unpredictable events and for this reason one of the most dangerous (Harp and Noble, 1993). The difficulty of identifying the precursory symptoms and rate, at which these events generally evolve make risk hard to the evaluation and management (Azzoni, 1995; Panizza, 1996). Even low magnitude events in terms of volume might reach high hazard levels and that is why Italian laws (Piani di Assetto Idrogeologico) always consider rock falls at the top of the hazard scale. Generally in rock fall hazard evaluation the face of the mountains, from which these events might occur are studied both from structural and geomechanical point of view (Castelli, 2006; ISRM, 1978). In order to mark the susceptible areas, the probable position of the rocks detachment from the face and their trajectory down the slope can be modelled by many well known computer codes (Azzoni et al., 1995; Guzzetti et al., 2002; Rocscience Inc., 2002; Stevens, 1998). However, very often, the major risk is not induced from rock

Published by Copernicus Publications on behalf of the European Geosciences Union. 


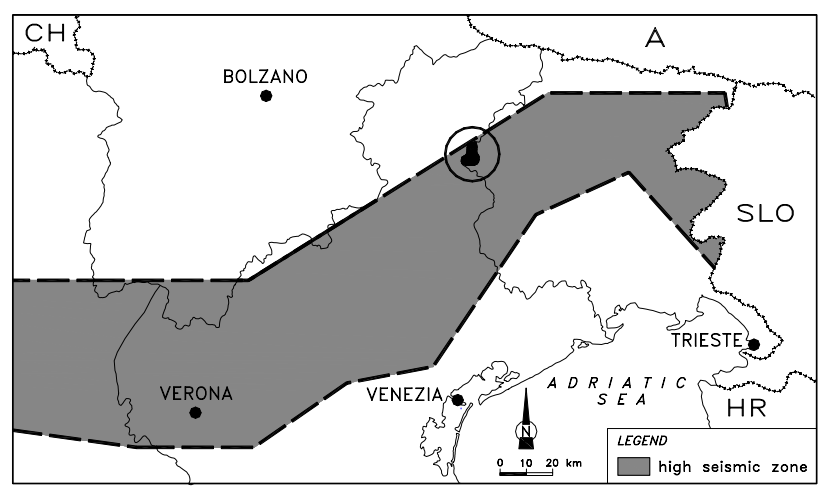

Fig. 1. General location of the studied area showing the high seismic zone based on Italy laws. The municipality of Erto and Casso is surrounded by circle.

faces but rather from old debris deposits that can be reactivated by changes in hydrologic conditions or by earthquakes (Govi and Sorzana, 1977). The case study of this work concerns the stability analysis of a huge rock fall accumulation, derived from a collapse occurred in 1674 on the southern slope of Mount Salta, located in one of the most seismic areas in Italy (Slejco et al., 1998), the Friuli Venezia Giulia Region, where in 1976 more than 1000 people died after a 6.4 magnitude earthquake (Weber and Courtout, 1978). On this landslide accumulation, a stability analysis has been carried out in order to define the potential volume of the debris cover that might be reactivated by a seismic event with a given magnitude and according to three different patterns of Earth acceleration. The expected magnitude of the earthquake used during the numerical simulation was defined from previous paleoseismic studies (Slejco and Rebez, 2002). The results so far achieved can be useful in the design of functional countermeasure works and/or to setup a civil defence evacuation plan in case of an earthquake.

The first phase of the research was mainly devoted to the geological, structural and geomorphological surveys, with particular attention to the landslide accumulation, which occurred in 1674.

In a second stage, numerical simulation of the slope deformations in dynamic conditions was carried out using distinct element method, along three significant cross-sections, in order to assess the evolution scenarios in case of seismic event. The cross-sections were selected, to simulate the behaviour of the debris cover along the trajectories that could affect the vulnerable elements present in the area. This activity is a part of the research carried out together with University of Udine and funded by Civil Defence Dept. of Friuli Venezia Giulia Region.

\section{Physical setting}

The study area is located on the boundary between Veneto and Friuli Venezia Giulia regions, in Vajont Valley, in the municipality of Erto and Casso, and is classified as highly seismic zone (Fig. 1). The villages are located exactly in front of the huge "Vajont Landslide" that collapsed the 9th of October 1963 into the artificial reservoir, killing almost 2000 peoples (Semenza, 2000). For these reasons the local authorities are very sensible to the problems concerning natural hazard, and especially into the risks induced by landslides. The Geological Risk of the area is essentially controlled by the Monte Salta landslide and by the stability of the huge landslide body (Semenza and Ghirotti, 1998). This deposit represents the main morphologic element of the slope behind the village of Casso, and since 1674 some portions were reactivated several times by sliding processes and minor rock falls.

The Mt. Salta-Borgà massif represents the last rampart of the Vajont Valley before its confluence in the main Piave Valley. The outcropping rock units belong to the Secondary age and ranged from lower Jurassic to upper Cretaceous (Winterer and Bosellini, 1981). The tectonic setting of the area is extremely complex and has been extensively studied after the Vajont catastrophic landslide. The most exhaustive studies were carried out on the left side of the Vajont valley (Kiersh, 1965; Mantovani et al., 1991; Hendron and Patton, 1995), but also the Mt. Salta area was deeply investigated, especially with regards to the huge rock fall phenomenon (Ghirotti and Marai, 1991; Ghirotti, 1994).

The main tectonic structures are related with the Alpine orogenesis that also caused, in a later phase, a set of faults striking North-South.

The Vajont valley extends along the axis of an asymmetric syncline, dipping to the East. The north side is controlled by the Mt. Borgà regional thrust, which uplifts Jurassic limestone on top of a Cretaceous formation, causing in the first unit a low angle flat fold, plunging southward (Semenza, 1960), (Fig. 2).

The geomorphologic evolution of the slopes is conditioned by the tectonic setting. In particular, the Mt. Borgà thrust is certainly the main conditioning factor that led to the weakening of the rock masses and the subsequent mass movements.

The source area of the Mt. Salta landslide is characterized by the presence of different scarps, distributed along tectonic discontinuities. The 1674 event scarps and the accumulation are still evident. The main scarp has a semicircular shape, delimited by steep cliffs, several meters high, carved in the Vajont limestone.

The landslide body that can be referred to the main event has a volume of approximately $2500000 \mathrm{~m}^{3}$ and occupies an area of $250000 \mathrm{~m}^{2}$; it is composed by blocks of different size, which reach a volume up to $800 \mathrm{~m}^{3}$. The deposit is arranged at an inclination up to $50^{\circ}$. The difference in altitude is relevant, ranging from $1875 \mathrm{~m}$ a.s.l. at Prà del Salta, 


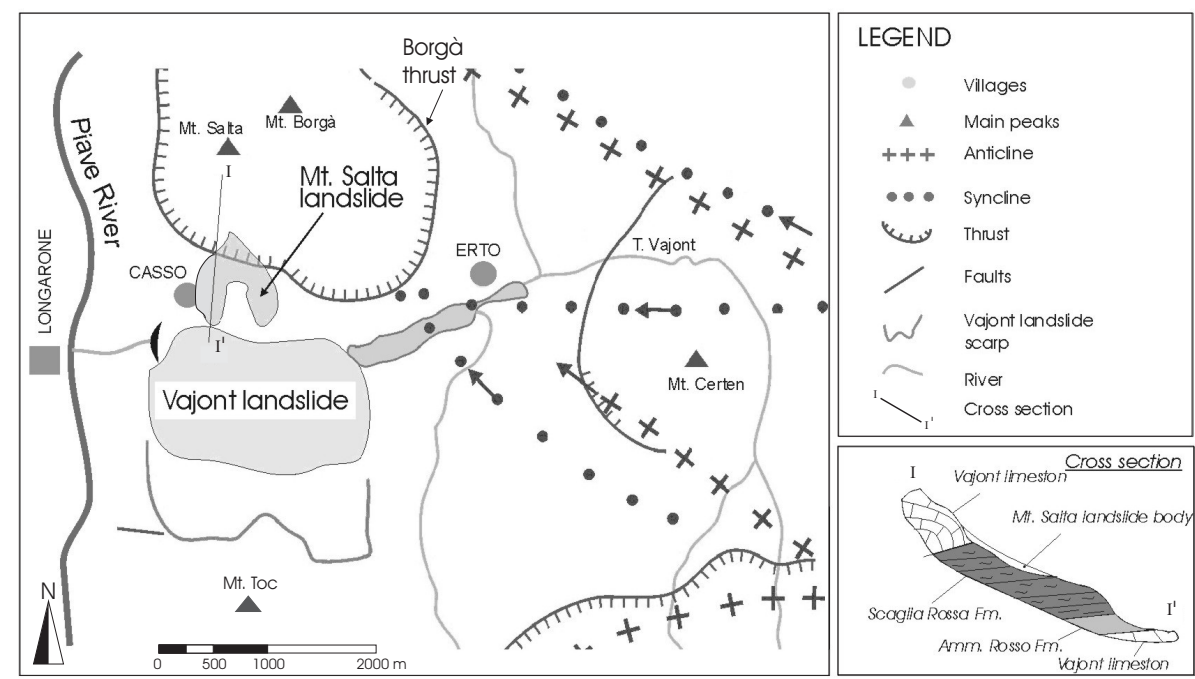

Fig. 2. Geological, tectonic and geomorphologic sketch of the study area.

down to $730 \mathrm{~m}$ on the national road. The distribution of the blocks, according to their dimensions, suggests that the kinematics of major Mt. Salta landslide event can be assumed as a rock avalanche (Evans and Hungr, 1993).The landslide body is partially covered by scree deposits; in fact, from the main and secondary scarps frequent rock fall and debris flow phenomena occur that feed thick talus that partially covers the older landslide deposit.

From the litological point of view, these deposits are homogeneous, and are composed of Vajont limestone debris. The texture is openwork, clast supported and there are no internal sedimentary structures.

\section{Stability analysis of the debris cover}

In order to carry out realistic model of the slope, it is necessary to represent accurately the physical conditions of the study area. For this reason, specific field investigations, photogrammetric analysis and detailed size distribution tests were carried out. Thanks to these procedures it was possible to divide the debris mass into 5 different granulometric classes, as presented in Table 1, and to achieve the requested accuracy, allowing for appropriate dimensioning of the numerical model mesh.

For the purpose of the study mentioned before, i.e. for evaluation of the risk scenario of the area in the earthquake condition, three cross-sections of the slope debris were chosen and numerically analysed: the first $\left(\mathrm{C}-\mathrm{C}^{\prime}\right)$ on the west, directly plunging over the village of Casso, the second ( $\left.\mathrm{A}-\mathrm{A}^{\prime}\right)$ on the east, that involves the road to Casso and the last (B$\mathrm{B}^{\prime}$ ), most dangerous, threatening directly the village (Fig. 3). The models of these sections were divided into continuous blocks, built of rock matrix and interacting along the discontinuities.

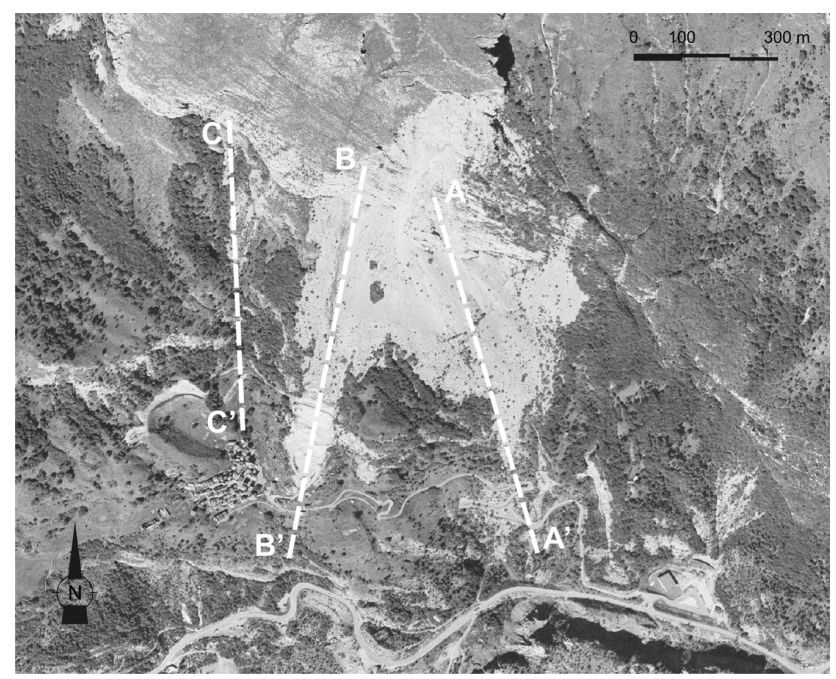

Fig. 3. The three numerically modelled cross sections of Monte Salta landslide slope.

The numerical simulation was carried out using distinct element method, which is coded in UDEC computer program (Itasca, 2004). UDEC is suited to study deformation and failure processes, directly related to the presence of discontinuities (Zabuski et al., 1999). The rock mass is modelled as a system of rigid or deformable blocks, interacting along so called "interfaces", which imitate discontinuities (Marcato et al., 2006). The behaviour of rock matrix and interfaces is described by laws of the continuous medium mechanics. Deformable blocks are divided into zones, which can change their shape, causing the change of block shape. As it is shown in Fig. 4, the final system can be totally different in comparison with the initial one. 
Table 1. The modified Wentworth (1922) grain size classification.

\begin{tabular}{ccccccc}
\hline $\begin{array}{c}\text { Granulometric } \\
\text { classes }\end{array}$ & $\begin{array}{c}\text { Large } \\
\text { boulders }(\%)\end{array}$ & $\begin{array}{c}\text { Medium } \\
\text { boulders }(\%)\end{array}$ & $\begin{array}{c}\text { Small } \\
\text { boulders }(\%)\end{array}$ & $\begin{array}{c}\text { Coarse } \\
\text { gravel }(\%)\end{array}$ & $\begin{array}{c}\text { Coarse } \\
\text { sand (\%) }\end{array}$ & $\begin{array}{c}\text { Coarse } \\
\text { silt }(\%)\end{array}$ \\
\hline I & 30 & 20 & 30 & 15 & 5 & - \\
II & 10 & 35 & 25 & 25 & 5 & - \\
III & 5 & 25 & 40 & 25 & 5 & - \\
IV & - & 25 & 40 & 30 & 5 & - \\
V & - & - & 20 & 65 & 10 & 5 \\
\hline
\end{tabular}

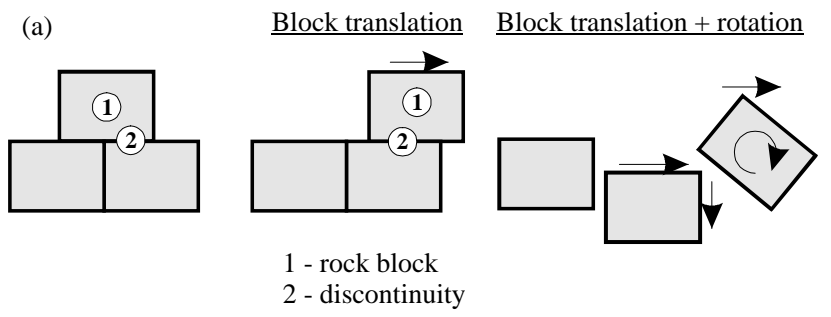

(b)

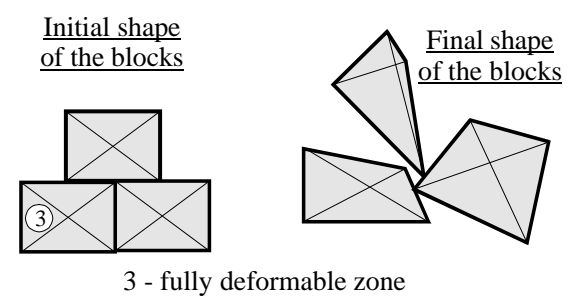

Fig. 4. Possible deformations and displacements of the blocks (a) rigid model, (b) fully deformable model.

The cross-section A-A', presented in Fig. 5 as an example, shows that according to the field investigation results block size changes along the cross-section. Following what expressed in Table 1, and in consequence to the output granulometric map of the entire debris deposit, the dimensions assumed in the model represent the size of the major percentage blocks in the reference class.

Block dimensions in the $\mathrm{A}-\mathrm{A}^{\prime}$ and $\mathrm{B}-\mathrm{B}^{\prime}$ cross-sections are differentiated, as they contain different granulometric classes, whereas in the $\mathrm{C}-\mathrm{C}^{\prime}$ cross-section they are uniform, as the deposit in this sector was described by only one granulometric class (IV), with grain size ranging between medium boulder and coarse sand.

\section{Modelling strategy}

The bedrock is modelled as an elastic medium and its internal deformations depend on the magnitude of elasticity parameters, i.e. shear and bulk moduli. Rock blocks and discontinuities in a sliding part of the slope exhibit elasto-plastic behaviour. The intact blocks are divided into fully deformable

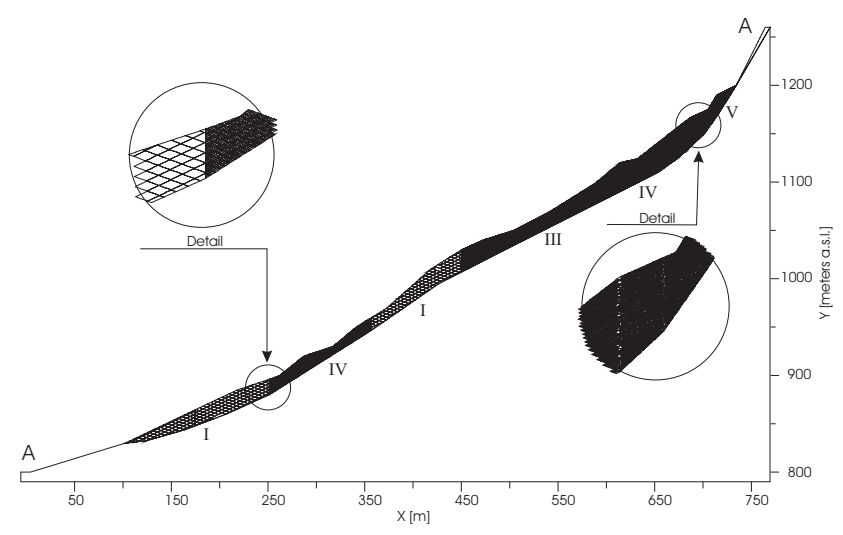

Fig. 5. Cross section A-A', splitting the slope into rock blocks (location - see Fig. 3). Roman numbers indicate the granulometric classes defined during field investigations and summarized in Table 1 .

zones and therefore can internally deform, according to the rules of elasto-plasticity theory. Such assumption agrees with the common practice, as the behaviour of geologic medium (rock) usually fulfil the laws of elasto-plasticity; it behaves elastically, when the stress level is low and plastically - when the plasticity limit is reached (Cundall, 1990; Starfield and Cundall, 1988). Elastic properties of the discontinuities in direction parallel and perpendicular to their course are described by shear and normal stiffness, respectively. These parameters determine the displacement ability along discontinuities, so they describe their deformational behaviour in elastic domain (similarly as the elasticity parameters of intact rock). The plasticity limit is described by CoulombMohr criterion. It was assumed that there is no difference between strength parameters, i.e. cohesion and angle of friction of rock and discontinuities. Due to such assumption, plastic deformations are possible in all directions, so the modelled discontinuities are not preferred failure directions (Zabuski and Marcato, 2005). These condition expresses the reality, as the orientation of the discontinuities is not constant but has chaotic character.

Geomechanical parameters of the bedrock and rock blocks, set in Table 2 are the same for the three cross- 
Table 2. Geomechanical parameters of the rock matrix.

\begin{tabular}{llccccccc}
\hline Zone & Model & $\begin{array}{c}\text { Unit weight } \\
{\left[\mathrm{kN} / \mathrm{m}^{3}\right]}\end{array}$ & $\begin{array}{c}\text { Bulk modulus } \\
{[\mathrm{kPa}]}\end{array}$ & $\begin{array}{c}\text { Shear modulus } \\
{[\mathrm{kPa}]}\end{array}$ & $\begin{array}{c}\text { Cohesion } \\
{[\mathrm{kPa}]}\end{array}$ & $\begin{array}{c}\text { Angle of friction } \\
{[\mathrm{deg} .]}\end{array}$ & $\begin{array}{c}\text { Dilation angle } \\
{[\mathrm{deg} .]}\end{array}$ & $\begin{array}{c}\text { Tension strength } \\
{[\mathrm{kPa}]}\end{array}$ \\
\hline Bedrock & Elastic & 22.0 & $8.33 \mathrm{E} 7$ & $3.85 \mathrm{E7}$ & - & - & - & - \\
Landslide & Elasto-plastic & 19.0 & $8.33 \mathrm{E} 6$ & $3.85 \mathrm{E} 6$ & 0 & 38 & 19 & 0 \\
\hline
\end{tabular}

Table 3. Geomechanical parameters of the discontinuities.

\begin{tabular}{llcccccc}
\hline Zone & Model & $\begin{array}{c}\text { Normal stiffness } \\
{[\mathrm{kN} / \mathrm{m}]}\end{array}$ & $\begin{array}{c}\text { Shear stiffness } \\
{[\mathrm{kN} / \mathrm{m}]}\end{array}$ & $\begin{array}{c}\text { Cohesion } \\
{[\mathrm{kPa}]}\end{array}$ & $\begin{array}{c}\text { Angle of friction } \\
{[\mathrm{deg} .]}\end{array}$ & $\begin{array}{c}\text { Dilation angle } \\
{[\mathrm{deg} .]}\end{array}$ & $\begin{array}{c}\text { Tension strength } \\
{[\mathrm{kPa}]}\end{array}$ \\
\hline Landslide & Elasto-plastic & $1.0 \mathrm{E} 7$ & $1.0 \mathrm{E} 7$ & 0 & 38 & 19 & 0 \\
\hline
\end{tabular}

sections. Parameters of the discontinuities are listed in Table 3 .

As the field tests of the strength parameters were not done, their values were assumed, with taking into account the properties of similar interlocked media. The lack of cohesion can be justified, as the contacts between the blocks are continuous, and "rock bridges" do not exist. The value of the friction angle equal to $38^{\circ}$ provides the equilibrium of the slope at present, but without significant stability "reserve". Moreover, the displacements are of order of millimetres, indicating the tendency to the interlocking of the rock grains and discontinuity irregularities (Bray, 1973). Such structure creates proper conditions for high friction resistance. As it is seen in the tables, the value of the dilatation angle is relatively high, although the flow rule is non-associated. Assuming high value of this angle it is expected, that during the advanced deformational processes the rock mass will "swell" and this supposition expresses dilatation angle equal to 50\% of friction angle. Elasticity parameters are relatively high, as the intact rock is hard and strong.

It is necessary to explain that the stable conditions of the whole slope, inclined in the upper part at ca. $50^{\circ}$, whereas the friction angle is equal $38^{\circ}$ are assured thanks to the supporting effect of the parts lying below. In other words, the blocks located below the most steeply inclined part have some "reserve" of resistance and can also carry the load exerted by the upper blocks. Moreover, the level of stresses is low (elasticity domain) and the limit equilibrium is not reached yet.

The water table was not considered in the model, since the blocky structure of the landslide body is highly permeable and no springs are visible on the slope surface.

Numerical simulations were performed for three crosssections of the slope. The earthquake effects were simulated in pseudo-dynamic mode, i.e. by increasing the acceleration in comparison to the magnitude of Earth acceleration "g" and applying also its horizontal component. The expected seismic acceleration was calculated in previous studies (Bragato

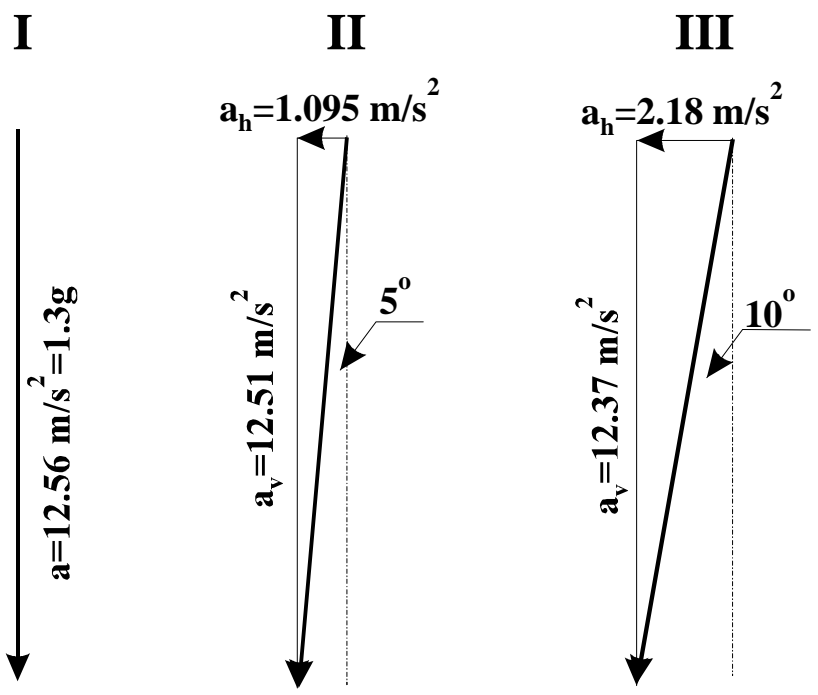

Fig. 6. Considered cases of seismic acceleration.

and Slejco, 2004) as equal to $0.28 \mathrm{~g}$ (where $\mathrm{g}=9.81 \mathrm{~m} / \mathrm{s}^{2}$ ). Three cases of acceleration were considered (Fig. 6). The only acting downwards vertical component, $\mathrm{a}=1.3 \mathrm{~g}$ was applied in first (I) case, i.e. vertical acceleration was increased at $30 \%$ with respect to the Earth acceleration. In II and III cases, horizontal component was added, by means of inclination of the resultant acceleration at $5^{\circ}$ and $10^{\circ}$ to the vertical, respectively. In all three cases displacements were calculated and failure phenomena registered, until equilibrium state was reached. In some cases the model failed and it was impossible to reach stable state, so the simulation was stopped arbitrary. 


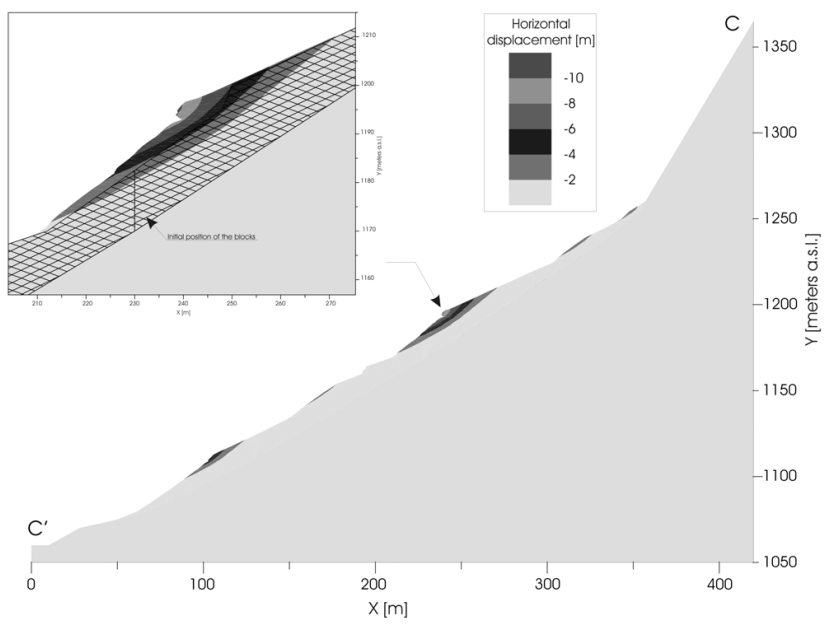

Fig. 7. Field of horizontal displacement in C-C' cross-section (location - see Fig. 3). Acceleration case II.

\section{Simulation results}

Only the results for cross-section $\mathrm{C}$ are discussed below as an example, as the results for both A and B cross-sections are similar to these presented here. In case I (vertical acceleration), only very small portion in the central, mostly inclined part of the slope moves more significantly and the model stabilises in a short time, and further displacement increments do not occur. In case II, larger portions of the slope start to move, but finally the system also reaches equilibrium state and the maximum displacement is equal to about $3 \mathrm{~m}$ as an effect of some shear stress increasing. The field of horizontal displacement for this case is shown in Fig. 7.

In case III, an inclination of the acceleration at $10^{\circ}$ to the vertical produces an extensive movement of the entire slope. As it is presented in Fig. 8, field of horizontal displacement is relatively uniform along the slope and the displacement magnitude depends first of all on the depth of the block location; the deeper the block the smaller the displacement. Equilibrium state in iteration process was not reached in this case and the simulation was thus stopped arbitrarily, when the maximum horizontal displacement was equal to approximately $20 \mathrm{~m}$. It means that stability of the deposits is definitively lost and the movements proceed continuously.

The results clearly prove that even relatively small horizontal acceleration triggered by an earthquake can be the reason of extensive failure of the slope. The later result, obtained for inclined acceleration seems to be more realistic than the first one (when only vertical acceleration was considered), as the presence of the horizontal acceleration component in the earthquake pattern is always highly probable.

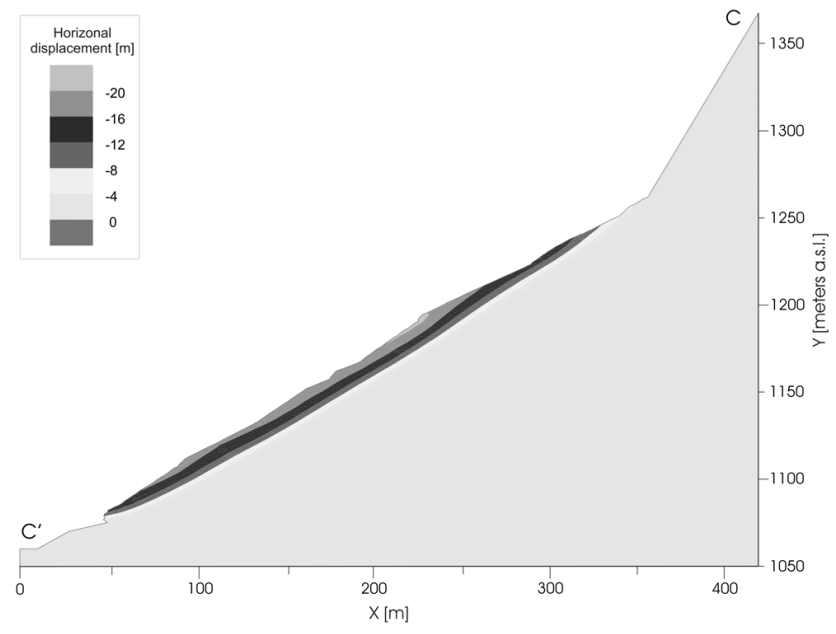

Fig. 8. Field of horizontal displacement in C-C $\mathrm{C}^{\prime}$ cross-section (location - see Fig. 3). Acceleration case III.

\section{Conclusions}

The presented methodology allows to evaluate the influence of an earthquake on the slope stability and possible failure mode in a relatively simple way.

The numerical simulation of the behavior of the debris deposits that mantle the southern slope of Mt. Salta proves high influence of the horizontal acceleration in case of earthquakes that could trigger instability phenomena. In fact, in the case of vertical seismic acceleration equal to $1.3 \mathrm{~g}$ only few centimetres displacements in very small portions of the slope can occur.

On the contrary, if a seismic acceleration with a horizontal component is applied, which is more probable in case of earthquake (scenarios II and III), the system loses stability and the debris moves extensively. It is thus evident on the base of presented results, that debris deposit can not be considered as stable during the earthquake shaking, but could be affected by significant remobilisation.

A realistic mitigation of the residual risk posed to the village of Casso, mainly directed to the protection of the urban area, could foresee to continue and enlarge the quarrying activity, in order to create a wide area that could contain the debris eventually remobilised in case of landslide event.

On the contrary, the protection of the road connecting the village with the main valley seems to be less feasible, as in the sector modelled in $\mathrm{C}$ cross-section, the road passes through the steep slope. The simulation results show that in case of a seismic event, the displaced material could not be retained by any structural countermeasure work, as its volume would be very large. Therefore, this trial clearly shows to the Civil Defence that there is a high probability that in case of seismic event the village could be isolated. 
Acknowledgements. The work presented in this paper was carried out with funding from National Research Council of Italy, International short mobility Program for scientist/researchers from Italian and Foreign Institutions, grant number 0050247/2006.

Edited by: F. Guzzetti

Reviewed by: J. L. Zezere and another anonymous referee

\section{References}

Azzoni, A.: Experimentally gained parameters, decisive for rock falls analysis. Int. J. Rock Mech. Min. Sci. Geomech., 28(2), 111-124, 1995.

Azzoni, A., La Barbera, G., and Zaninetti, A.: Analysis and prediction of rockfalls using a mathematical model. Int. J. Rock Mech. Min. Sci. Geomech., 32(7), 709-724, 1995.

Bragato, P. L. and Slejco, D.: Empirical ground motion attenuation relations for the eastern Alps in the magnitude range 2.5-6.3, B. Seism. Soc. Am., 95, 252-276, 2004.

Bray, J. W.: Study of Jointed and Fractured Rock, Rock Mech. Eng. Geol., 5(167), 119-136 (part I), 197-216 (part II), 1973.

Castelli, E.: Frane di crollo, Progetto Interreg III A 2000-2006, 4864, 2006.

Cundall, P. A.: Numerical Modelling of Jointed and Faulted Rock, Mechanics of Jointed and Faulted Rock, 11-18, Balkema, Rotterdam, 1990

Evans, S. G. and Hungr, O.: The assessment of rockfall hazard at the base of talus slopes, Canadian Geotechnical J., 30, 620-636, 1993.

Ghirotti, M. and Marmai, M.: An outline of Cima Salta Mt. rock slides and topplings. Prev. and Control of landslides other mass movements, Comm. Of the European Communities, 1991.

Ghirotti, M.: L'antica frana del Monte Borgà e primi risultati del monitoraggio dell'area di Prà de Salta (Casso PN), Quaderni di Geologia Applicata, 23, 121-128, 1994.

Govi, M. and Sorzana, P. F.: Effetti geologici del terremoto: frane, in: Studio geologico dell'area maggiormente colpita dal terremoto friulano del 1976, edited by: Martinis, B., 1977,, Riv. Ital. Paleont. Stratigr., 83, 329-368, 1977.

Guzzetti, F., Crosta, G. B., Detti, R., and Agliardi, F.: "STONE: a computer program for the three-dimensional simulation of rockfalls", Comp. Geosci., 28(9), 1079-1093, 2002.

Harp, E. L. and Noble, M. A.: An engineering rock classification to evaluate seismic rock fall susceptibility and its application to the Wasatch Front, B. Assoc. Eng. Geologist, 30, 3, 1993.

Hendron, A. J. and Patton Jr., F. D.: The Vaiont Slide, a geotechnical analysis based on new geologic observations of the failure surface, Department of Army, US Army Corps of Engineers, Contract, DACW39-79-C-0063, 1985.

International Standard of Rock Mechanics (ISRM): Suggested methods for the quantitative description of discontinuities in rock masses, Int. J. Rock Mech. Min. Sci. Geomech. Abstr., 15, 319368,1978
ITASCA, C. G.: Universal Distinct Element Code 4.0, User's Manual, Minneapolis, 2004.

Kiersch, G. A.: Vaiont reservoir disaster, Civil Engineering, 34, 32 39, 1964.

Mantovani, F., Bollettinari, G., and Ghirelli, C.: The Vaiont Rock landslide, in: 1991, European experimental course on applied Geomorphology, edited by: Panizza, M., Soldati, M., Coltellacci, M. M., Proceedings, 2, 65-76, 1991.

Marcato, G., Silvano, S., and Zabuski, L.: Modellazione di ammassi rocciosi instabili con il metodo degli elementi distinti, Giornale di Geologia Applicata, 2, 87-92, 2006.

Panizza, M.: Environmental Geomorphology, Developments in Earth Surface Process, 4, Elsevier, 268 pp., 1996.

ROCSCIENCE INC.: Rockfall. Risk analysis of falling rocks on steep slopes, Toronto, Canada, 59 pp., 2002.

Slejko, D. and Rebez, A.: Probabilistic seismic hazard assessment and deterministic ground shaking scenarios for Vittorio Veneto (N.E. Italy), Bollettino di Geofisica Teorica ed Applicata, 43, 263-280, 2002.

Slejko, D., Peruzza, L., and Rebez, A.: Seismic hazard maps of Italy, Annali di Geofisica, 41, 183-214, 1998.

Semenza, E.: Nuovi studi tettonici nella Valle del Vajont e zone limitrofe, Rend. Acc. Naz. Lincei, Classe Sc. Fis., Mat. e Nat., serie VIII, vol. XXVIII, 2, 223-229, 1960.

Semenza, E. and Girotti, M.: Vajont-Longarone 34 anni dopo la catastrofe, Annali dell'Università di Ferrara, serie VII, 4, 63-94, 1998.

Semenza, E.: La storia del Vajont raccontata dal geologo che ha scoperto la frana, Tecomproject Ed., Ferrara, Italy, 2000.

Starfield, A. M. and Cundall, P. A.: Towards a Methodology of Rock Mechanics Modelling, Int. J. Rock. Mech. Min. Sci. Geomech. Abstr, 25(3), 99-106, 1988.

Stevens, W. D.: Rockfall. A tool for probabilistic analysis, design of remedial measures and prediction of rockfall, Thesis for the degree of Master of Applied Science Graduate, Dept. of Civil Engineering, University of Toronto, Canada, 1-28, 1998.

Weber, C. and Courtout, F.: Le seisme du Frioul (Italie, 6 mai 1976) dans son contex sismotectonique, Rev. Geogr. Phys. Geol. Dyn., 2, 247-258, 1978.

Winterer, E. L. and Bosellini, A.:Subsidence and sedimentation on a Jurassic Passive Continental Margin, Southern Alps, Italy, AAPG Bull., 65, 394-421, 1981

Zabuski, L. and Marcato, G.: Numerical modelling of the landslide processes using discontinuous approach, Proc. Int. Conf. "Mass Movement Hazard in Various Environments", Polish Geological Institute Centre of Excellence REA, 20, 119-124, 2005.

Zabuski, L., Thiel, K., and Bober, L.: Osuwiska we fliszu Karpat polskich. Geologia, Modelowanie, Obliczenia statecznoci (Landslides in Carpathian Flysch. Geology, Modelling, Stability calculations), Wydawnictwo IBW PAN, Gdansk, Poland, 1999. 